\title{
An Experimental Investigation of Heating in Induction Motor under Open Phase Fault
}

\author{
Mahdi Atig, Mustapha Bouheraoua, Arezki Fekik \\ Engineering Advanced Technology Laboratory, Mouloud Mammeri University of Tizi-Ouzou, Algeria
}

\begin{tabular}{l} 
Article Info \\
\hline Article history: \\
Received Dec 30, 2017 \\
Revised Jan 19, 2018 \\
Accepted Feb 11, 2018 \\
\hline
\end{tabular}

Keyword:

Heating

Induction motor

Open phase

Stator currents

Thermal analysis

\begin{abstract}
Although a three-phase squirrel cage induction motor is known by its qualities of robustness and low cost of construction. However, this machine can be affected by potential defects that affect the production, safety, quality of service and profitability of installations. However, to show the behavior of induction motor in different operating modes, the studying of this machine is very important. This paper presented the results of an experimental investigation to see the impact of the open phase fault on the thermal behavior in the $2.2 \mathrm{~kW}$ three phase squirrel cage induction motor, and to display the stator current waveforms with healthy and faulty conditions under different loads.
\end{abstract}

Copyright $\odot 2018$ Institute of Advanced Engineering and Science. All rights reserved.

\section{Corresponding Author:}

Mahdi Atig,

Engineering Advanced Technology Laboratory (LATAGE),

Mouloud Mammeri University,

BP: 15000, Tizi-Ouzou, Algeria.

Email: mahdiatig36@yahoo.fr

\section{INTRODUCTION}

The three-phase induction machine is one of the most popular rotating electrical machines used in industrial driven equipment. They carry out their function for many years and adapt themselves to different performances. Moreover, these motors are widely used in many industrial processes, such as electric power stations, oil refineries, and factories, due to their simplicity, rugged construction and relatively low manufacturing costs. However, this machine can be affected by potential defects that affect the production, safety, quantity of service and profitability of installations, such as stator faults, broken rotor bars and end ring faults, bearings and the eccentricity-related faults; which are the most common failures and thus require special attention. For this reason, the presence of these failures creates an unbalance in the temperature distribution of the motor, and it is also noted that heating in induction motors must be kept below certain limits, because as a rule of thumb for every $10^{\circ} \mathrm{C}$ increase in temperature the age of insulation life is reduced by $50 \%$ [1]. For that, the appearance of the constraints mentioned previously requires an important need for accurate estimation of temperature, particularly in those hot spots where a risk of adverse thermal conditions increases. However, to predict the machine temperature with and without defect, thermal models are employed that can be used to improve the machine design or to determine load ability during different operating conditions. Furthermore, the determination of temperature in an induction motor can follow two possible approaches. The first involves an indirect estimation of temperature through the use of thermal modeling. The second approach involves an experimental investigation which allows the measurement of temperature for different load and supply conditions.

In the past decades, there have been continuing efforts in studying thermal induction motors with and without faults. In references [2]-[7], the authors deal with the thermal modeling of an induction motor of Totally Enclosed Fan Cooled "TEFC" design for healthy operations. The analysis and the results reported in 
these papers allow giving some general guidelines useful for obtaining an accurate thermal modeling of these machines. On the other hand, several authors studied the behavior of the induction machine in the presence of defects. For example, X. Ying [8], presents the influences of broken bars located at different relative positions in an induction motor. This paper is intended to study the electromagnetic and thermal fields of this machine, when operating in conditions of symmetrical and asymmetrical rotor. Moreover, Z. Liu and all [9], presents a coupled electromagnetic and thermal field analysis of a doubly fed induction generator with a focus on winding faults; this investigation is intended to analyze the characteristics of the magnetic field, temperature distribution and the heat flow during healthy and faulty operations. However, reference [10], has investigated the electromagnetic and thermal behavior for a multi-domain of an induction motor with stator core fault. In addition, L. Beran [11], conducted a thermal study on separate parts of the stator winding of a low power induction motor, with short-circuit current failures.

Out of these defects, the open phase fault is much specified in electrical machines. When one phase is lost, a phase loss occurs. Typically, this defect may be caused by a blown fuse, a thermal overload, a broken wire, a worn contact or a mechanical failure. A phase loss that goes undetected can rapidly result in unsafe working conditions, equipment failures, and costly downtime. However, the worst consequence of an open circuit fault in a safety-critical application would be a serious accident involving loss of human life resulting from an abrupt shutdown of the drive's operation. In this issue, several researches were carried out in order to study the impacts of open phase fault on the electrical machine behavior. Among these works, the paper [12], has investigated the operation of five-phase induction motor after loss of one phase of feeding source. The attention is paid to the waveforms of the currents in individual stator phases, the increase in torque pulsations and the decrease of speed in emergency operation after the disconnection of a faulty phase of the source. In reference [13], the authors investigated the vector control of a star-connected three-phase induction motor under the stator winding open-phase fault. In references [14], [15], the authors deal with the modeling of a three-phase induction motor under open-phase fault using the Matlab/Simulink implementation. However, it was found that Matlab/Simulink is more convenient in terms of simplicity in structure and modeling. Moreover, the paper [16], proposes a thermal investigation of five-phase permanentmagnet motor, considering the open-circuit fault of both one and two phases.

Indeed, the aim of our study is to make a cheap and reliable protection system for three-phase squirrel cage induction motor. The protection system should protect the motor from open phase fault and thermal protection. But, before proposing the protection system that protects the machine if any of the phases, out of the three phases is missing or if the temperature of the motor during operation exceeds the threshold value. It is important to have some information on the temperature distribution in the motor. However, this article presents an experimental study to measure the temperature in the induction motor, and to display the stator currents of a three-phase squirrel cage induction motor with one open phase fault. However, in this paper two types of experimental tests have been carried out:

a. When supplying a healthy induction motor with a $50 \mathrm{~Hz}$ sinusoidal supply.

b. When supplying the induction motor with $50 \mathrm{~Hz}$ sinusoidal supply with the occurrence of a fault.

\section{EXPERIMENTAL PROCEDURE}

In order to measure the characteristics mentioned previously, a test bench has been realized as shown in Figure 1. The experimental test rig is composed of a $2.2 \mathrm{~kW}$ three phase squirrel cage induction motor. The specification of test motor is shown in Table 1. The winding is a single-layer winding. The induction motor is mechanically coupled to a separately excited DC machine for loading processes. The load on the machine can be varied by varying the excitation of a DC machine. The open phase fault is created as shown in Figure 2. The temperature measurements are obtained using the thermocouples placed as shown in Figure 3 (1: frame, 2: stator iron-frame, 3: stator teeth, 4: slot winding, 5: end winding no cooled side, 6: end winding cooled side). Furthermore, during the tests the motor temperature is measured several times (every 3 minutes or every 10 minutes depending on the operating condition). In addition, the stator current waveforms were recorded by using an oscilloscope.

Table 1. Specification of Test Motor

\begin{tabular}{cc}
\hline Parameters & Values \\
\hline Rated speed & $1420 \mathrm{rpm}$ \\
Rated voltage & $380 \mathrm{~V}$ \\
Rated current & $5.2 \mathrm{~A}$ \\
Rated Torque & $15 \mathrm{Nm}$ \\
Connection & $\Delta$ \\
Insulation class & $\mathrm{F}$ \\
\hline
\end{tabular}




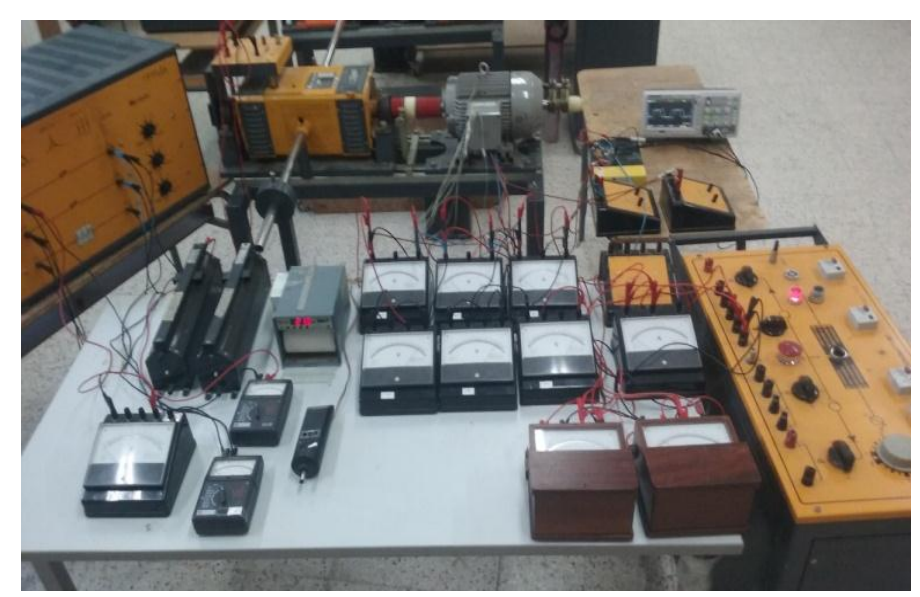

Figure 1. Motor during the experimental tests

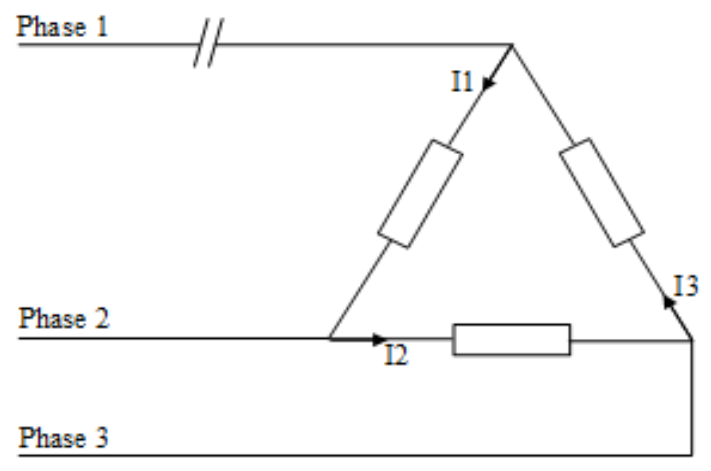

Figure 2. The schematic of an imbalance in which the phase 1 is opened

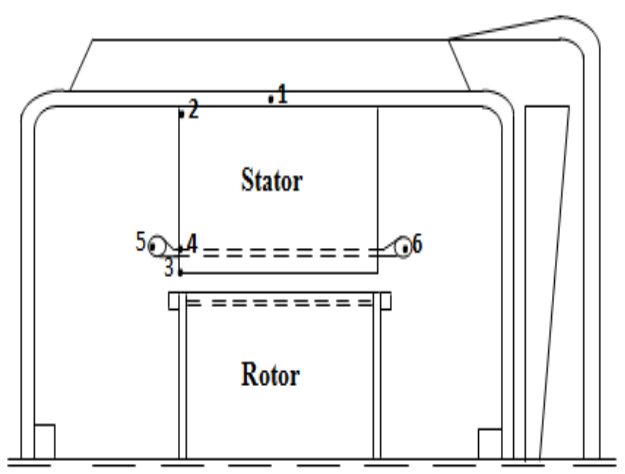

Figure 3. Location of sensors

\section{RESULTS AND DISCUSSIONS}

In this section, the experimental results obtained from the three phase squirrel cage induction motor with an open phase fault are presented. These results were compared for both healthy and faulty operations for two loads conditions $5.4 \mathrm{Nm}$ and $9.1 \mathrm{Nm}$. But, to not exceed the rated temperatures of the induction motor, we initially performed a test with full load conditions.

\subsection{A full load test}

To not exceed the rated temperatures of the machine, it is necessary to develop a thermal test with a full load. During this test, the motor is operated at rated voltage, current and frequency. The rated load of the motor is about $15 \mathrm{Nm}$ with class $\mathrm{F}$ insulation. As an illustration, Figure 4 shows the heating curves corresponding to each point were obtained with sinusoidal supply and under full load conditions. In this figure we can see that, at the starting point the temperature is uniform and equal to the ambient temperature. Then, after few operating seconds, the temperatures rise gradually. when steady-state is reached, it is noticed that the temperature in the motor is highest at the end-winding, no cooled side $\left(87.1^{\circ} \mathrm{C}\right)$ then in the end winding cooled side $\left(83.8{ }^{\circ} \mathrm{C}\right)$, slot winding $\left(83{ }^{\circ} \mathrm{C}\right)$, stator teeth $\left(79.5{ }^{\circ} \mathrm{C}\right)$, stator iron-frame $\left(59.9^{\circ} \mathrm{C}\right)$ and finally in the frame $\left(54.2^{\circ} \mathrm{C}\right)$. It should be noticed that the time-constant of heating after 110 minutes of operation, is weaker than that corresponding to the beginning of the test. 


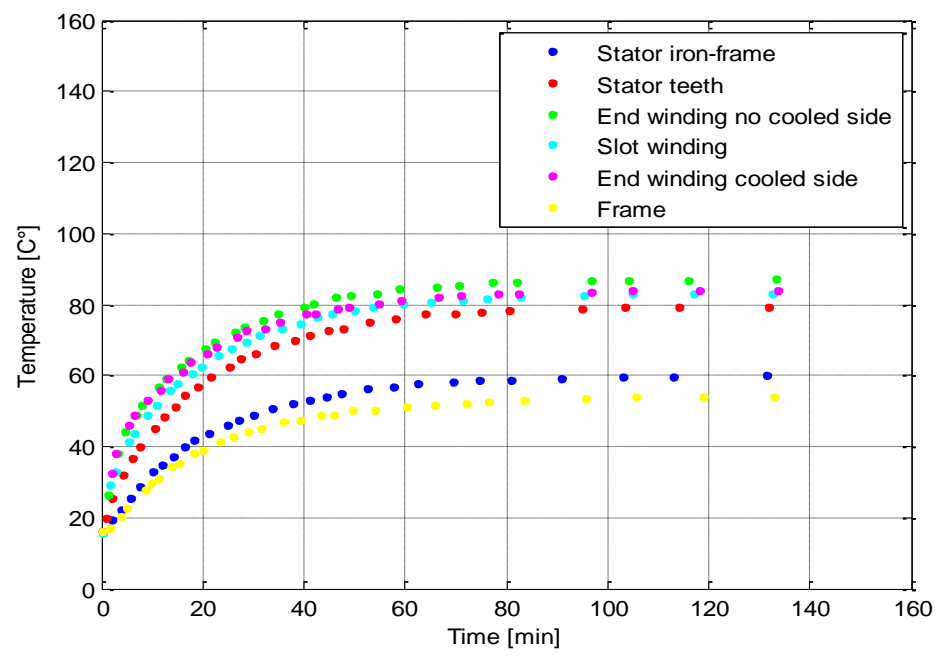

Figure 4. Heating curves for healthy operating conditions with a full load test

\subsection{A load of $5.4 \mathrm{Nm}$}

To avoid exceeding the machine's rated temperatures, we will gradually increase the load on the machine. Initially, we will impose a load of $5.4 \mathrm{Nm}$. The current waveforms of the coils I1, I2 and I3 obtained for a delta-connected three phase induction motors under open-phase fault for healthy and faulty operating conditions are shown in Figure 5, Figure 6 and Figure 7. If the balanced induction motor is fed from balanced three phase power system, the rms value of motor current is $2.1 \mathrm{~A}$, approximately.

After the occurrence of the open phase 1, we noted that the machine is operating in degraded mode that creates a remarkable unbalance in the motor, as can be seen from the curves of Figures 5, 6 and 7. It is found that the rms stator currents I1, I2 and I3 become 1.9 A, 3.35 A and 1.9 A respectively. So, we can note that the results obtained from this study are as expected because in our case the windings are coupled in delta configuration and in the presence of this defect, we will have two windings having the same current, in parallel with the third winding. On the other hand, in the researches [13-15], the authors deal with the modeling of the star-connected three-phase induction motor. However, the presence of the open phase fault in the star coupling, leads to a loss of the phase, which leads to a complete loss of the coil $(\mathrm{I}=0 \mathrm{~A})$.

In order to see the impact of the open phase of the temperature distribution in the induction motor, we performed the opening of phase 1, 2 and 3 respectively. However, Figure 8, Figure 9, 10 and Figure 11 shows the evolution of temperatures, particularly in those hot spots where a risk of adverse thermal conditions increases. Furthermore, Table 2 shows the experimental measurements of the temperatures in the stator teeth, slot winding, end-winding no cooled side and in the end winding cooled side. It can be seen that the open phase results in a temperature increase up to $49 \%$, depending on the phase affected by the fault. For this particular application, the end winding no cooled side has the highest increase. This reflects the large increase in copper losses in the windings. Consequently, this increase in temperature may lead to accelerated degradation of the insulation material within the machine.

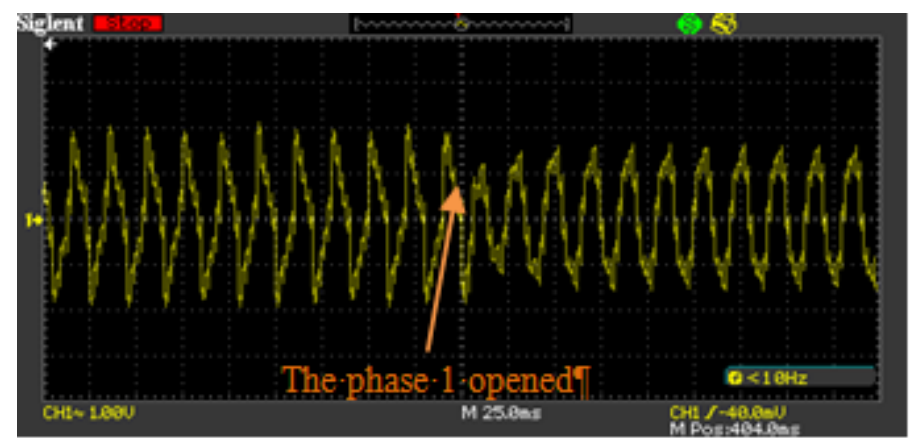

Figure 5. The current I1 waveform with a load of 5.4 Nm for healthy and faulty operating conditions 


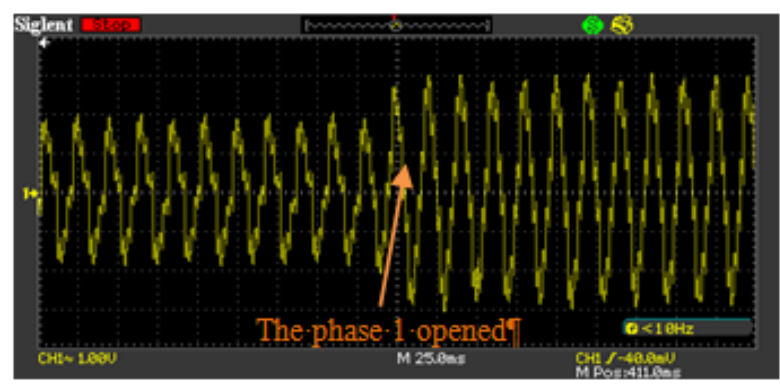

Figure 6. The current $\mathrm{I} 2$ waveform with a load of $5.4 \mathrm{Nm}$ for healthy and faulty operating conditions

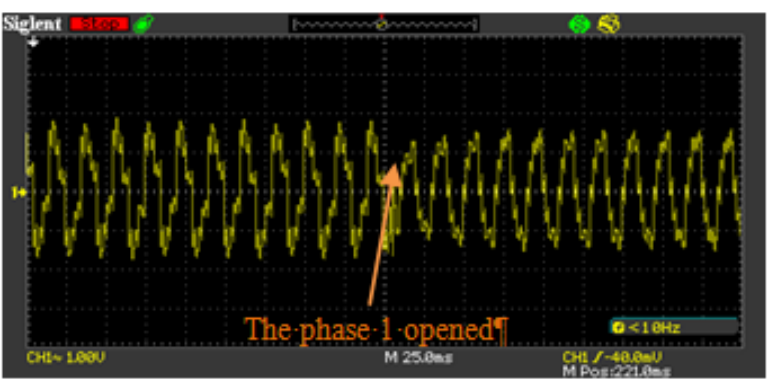

Figure 7. The current I3 waveform with a load of $5.4 \mathrm{Nm}$ for healthy and faulty operating conditions

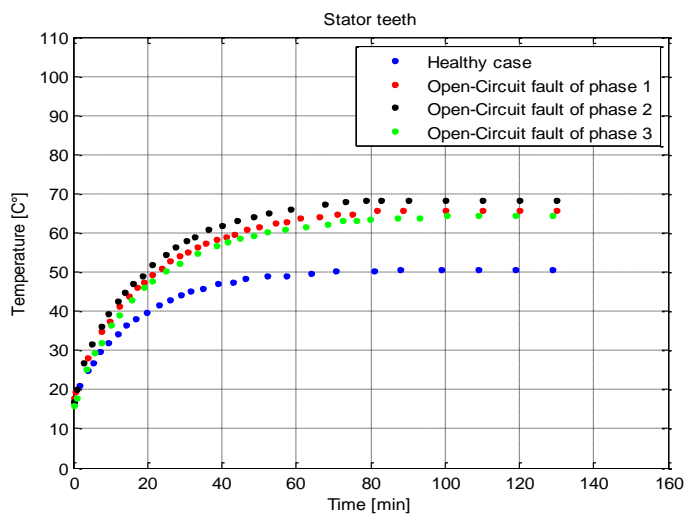

Figure 8. Stator teeth temperature comparison with a load of $5.4 \mathrm{Nm}$

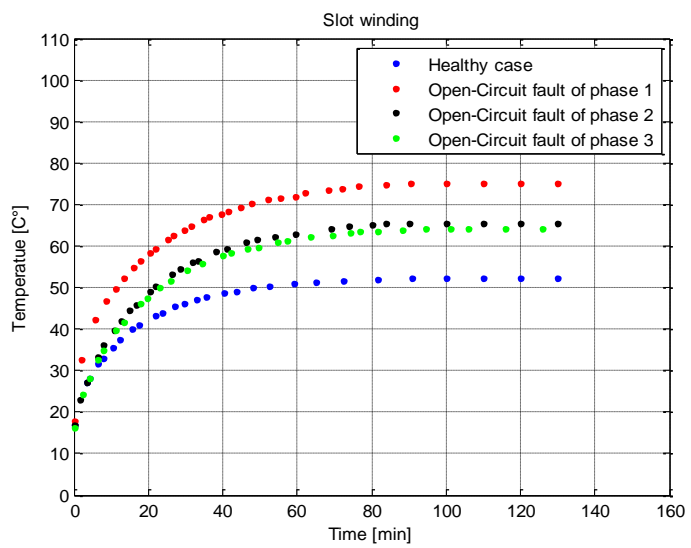

Figure 9. Slot winding temperature comparison with a load of $5.4 \mathrm{Nm}$ 


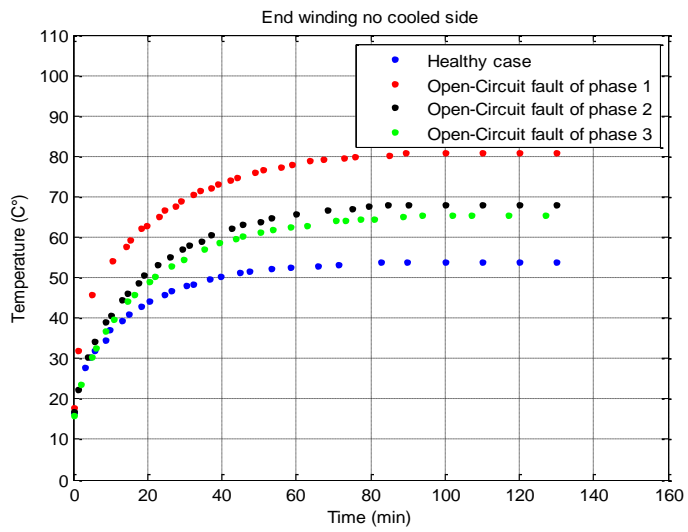

Figure 10. End winding no cooled side temperature comparison with a load of $5.4 \mathrm{Nm}$

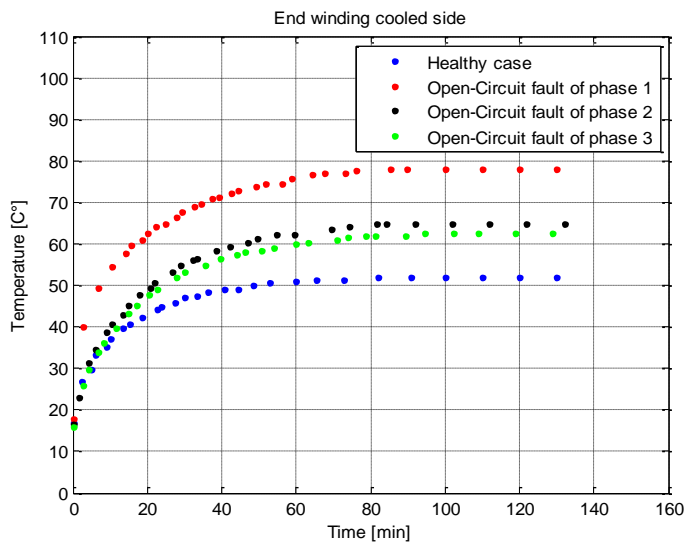

Figure 11. End winding cooled side temperature comparison with a load of $5.4 \mathrm{Nm}$

Table 2. Comparison between Temperatures with a Load of $5.4 \mathrm{Nm}$

\begin{tabular}{ccccc}
\hline Locations & $\begin{array}{c}\text { Healthy case } \\
\text { Temp }{ }^{\circ} \mathrm{C}\end{array}$ & $\begin{array}{c}\text { Open phase } 1 \\
\text { Temp }{ }^{\circ} \mathrm{C}\end{array}$ & $\begin{array}{c}\text { Open phase } 2 \\
\text { Temp }{ }^{\circ} \mathrm{C}\end{array}$ & $\begin{array}{c}\text { Open phase } 3 \\
\text { Temp }{ }^{\circ} \mathrm{C}\end{array}$ \\
\hline Stator teeth & 50.8 & 65.9 & 68.5 & 64.4 \\
Slot winding & 52.2 & 75.1 & 65.6 & 64.2 \\
End winding no cooled side & 53.9 & 80.8 & 68 & 65.3 \\
End winding cooled side & 52.1 & 78.1 & 64.9 & 62.4 \\
\hline
\end{tabular}

\subsection{A load of $9.1 \mathrm{Nm}$}

The test performed in this part is the same as that of $5.4 \mathrm{Nm}$, the phases 1,2 and 3 are opened respectively. However, the current waveforms are the same as of Figure 5, Figure 6 and Figure 7. Consequently, the increase of the load leads to an increase of the electric current. The value of the currents measured before the apparition of the fault is $2.3 \mathrm{~A}$, on another side the presence of a defect causes an imbalance of the currents in a similar manner with the above test which are 2.2 A, $4.3 \mathrm{~A}$ and $2.2 \mathrm{~A}$. For this test the power input is more important, which, causes a redistribution of the rises in the temperatures for the various elements of the motor. Consequently, this fault causes a notable increase in the temperature, in particular, in the end winding no cooled side. Indeed, Figure 12, Figure 13, Figure 14 and Figure 15 show the variation of temperatures in the stator teeth, slot winding, end winding no cooled side and in the end winding cooled side. Furthermore, the table 3 shows the results obtained for this test, it can be seen that the open phase fault of the motor results in a temperature increase up to $50 \%$ depending on the phase affected by the fault. For this particular application, the end winding no cooled side has the highest increase for the open phase 1, 2 and 3 respectively. In addition, according to the results obtained previously, we noted that the hot spot reached a temperature of $80.8{ }^{\circ} \mathrm{C}$ with a load of $5.4 \mathrm{Nm}$ and $123{ }^{\circ} \mathrm{C}$ with a load of $9.1 \mathrm{Nm}$, therefore with a rise of $42.2{ }^{\circ} \mathrm{C}$ for a difference of $3.7 \mathrm{Nm}$. Since the rated load of the induction motor is about $15 \mathrm{Nm}$ with class $\mathrm{F}$ insulation, it is clear that the open phase at full load becomes impossible, because the temperature will exceed the rated temperature of the motor. However, research [16], in which a finite element 
thermal analysis has been carried out both in healthy mode and in the event of the open circuit faults confirms our results. It is shown that the maximum temperature rise is obtained in the coils with the open phase fault.

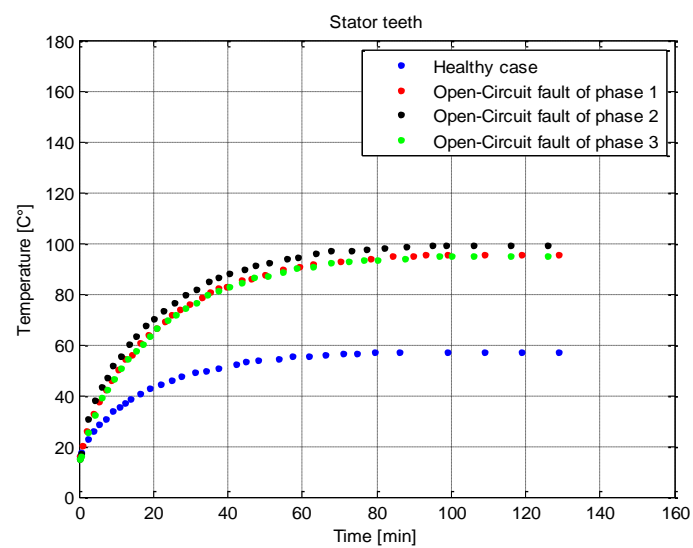

Figure 12. Stator teeth temperature comparison with a load of $9.1 \mathrm{Nm}$

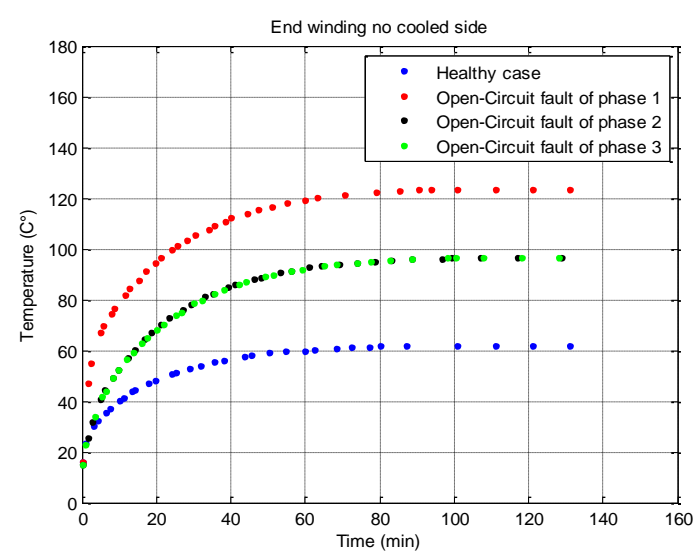

Figure 14. End winding no cooled side temperature comparison with a load of $9.1 \mathrm{Nm}$

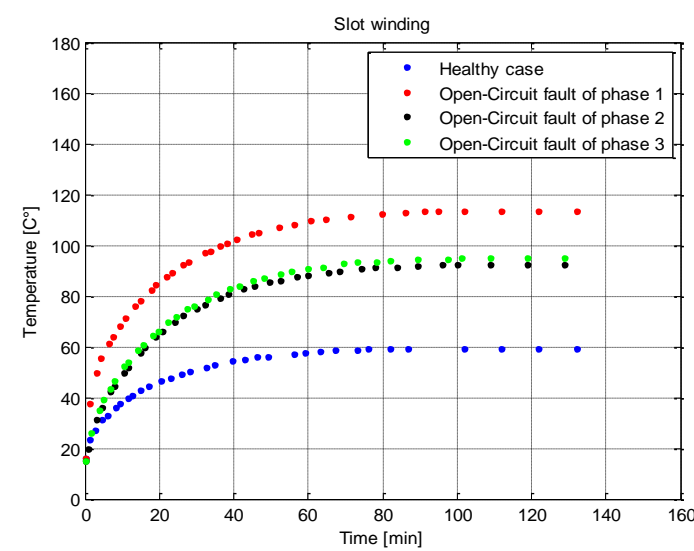

Figure 13. Slot winding temperature comparison with a load of $9.1 \mathrm{Nm}$

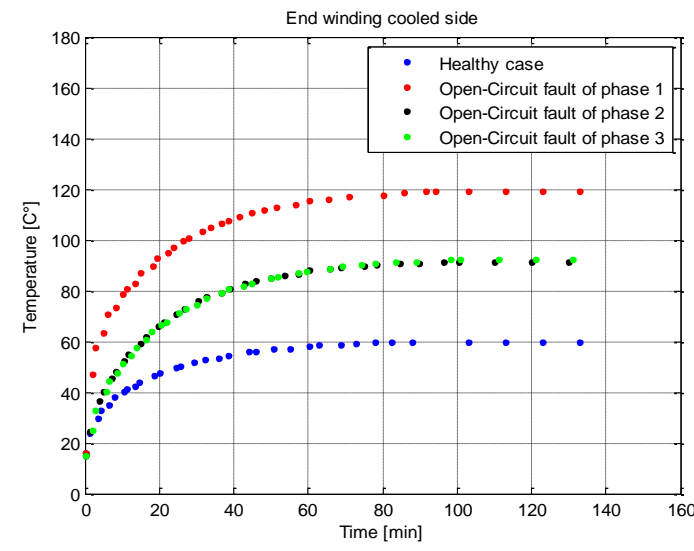

Figure 15. End winding cooled side temperature comparison with a load of $9.1 \mathrm{Nm}$

Table 3. Comparison between Temperatures with a Load of 9.1 Nm

\begin{tabular}{ccccc}
\hline Locations & $\begin{array}{c}\text { Healthy case } \\
\text { Temp }{ }^{\circ} \mathrm{C}\end{array}$ & $\begin{array}{c}\text { Open phase } 1 \\
\text { Temp }{ }^{\circ} \mathrm{C}\end{array}$ & $\begin{array}{c}\text { Open phase } 2 \\
\text { Temp }{ }^{\circ} \mathrm{C}\end{array}$ & $\begin{array}{c}\text { Open phase } 3 \\
\text { Temp }{ }^{\circ} \mathrm{C}\end{array}$ \\
\hline Stator teeth & 57.2 & 95.3 & 99.2 & 95.2 \\
Slot winding & 59.2 & 113.5 & 92.4 & 95.2 \\
End winding no cooled side & 61.7 & 123.4 & 96.6 & 96.6 \\
End winding cooled side & 59.9 & 119 & 91.5 & 92.3 \\
\hline
\end{tabular}

\section{CONCLUSION}

In this work we have established a literature search on some defects that can occur in three-phase squirrel cage induction motors. Then we focused on an experimental study for a delta connected induction machine affected by an open phase fault. Firstly, to not exceed the rated temperatures of the induction motor, a thermal test with a full load is presented. Secondly, the influence of the open phase fault on the motor is shown, for two loads conditions. Stator currents and the temperature of the motor for healthy and faulty operations are presented. Hence, from these results, it was found that this type of defect causes disturbances leading to an unbalance in the motor. So, providing a protection system is very important in industries. After having the impact of the phase opening on the thermal behavior of the induction machine, we noticed that the motor can continue to run when one phase of the supply gone out of service. At this condition the motor 
continues to run, but the motor will heat up quickly and it should be protected. For this condition, it is necessary to develop a reliable, fast and efficient system for induction motor protection. This protection of the induction motor from open phase fault provides the smooth running of machine which also improves its lifetime and efficiency. Furthermore, continuity of service is an important and essential quality that each system must have today to meet the needs of the user. For this, it is necessary to develop a control that can operate the motor with two phases only.

On the other hand, the induction motor winding failures due to stator insulation breakdown has been found to be one of the major causes of motor failure. The induction motor insulation life is affected by thermal, electrical, and mechanical stresses, as well as environmental conditions. Moreover, the thermal stress is considered to dominate other stresses. That is, the insulation aging process will depend on the magnitude and duration of the operating temperature. The winding insulation has a specific lifetime, and it deteriorates with time due to thermal stresses. Therefore, the induction motor life can be predicted by estimating the stator winding insulation life. For this reason, on the basis of this result, while wishing to estimate the lifetime of this machine in the presence of the open phase fault for different loads.

\section{ACKNOWLEDGEMENTS}

The authors would like to thank the members of Electrical Engineering Advanced Technology Laboratory (LATAGE) for their support during the realization of this work.

\section{REFERENCES}

[1] O. F. Jasim, "An extended induction motor model for investigation of faulted machines and fault tolerant variable speed drives," Thesis submitted to the University of Nottingham for the degree of Doctor of Philosophy, departement of electrical and electronic Engineering, UK, Oct 2009.

[2] A. Boglietti, et al., "A simplified thermal model for variable-speed self-cooled industrial induction motor," IEEE Transaction on Industrial Applications, vol. 39, pp. 945-952, Jul/Aug 2003.

[3] S. Mezani, et al., "Finite element thermal modeling of an induction motor," Electric Power Components and Systems, vol. 29, pp. 821-834, 2001.

[4] W. H. Tang, et al., "A simplified transformer thermal model based on thermal-electric analogy," IEEE Transaction on Power Delivery, vol. 19, pp. 1112-1119, Jul 2004.

[5] J. F. Trigeol, et al., "Thermal modeling of an induction machine through the association of two numerical approaches," IEEE Transactions on Energy Conversion, vol. 21, pp. 314-323, Jun 2006.

[6] M. Bouheraoua et al., "A more refined thermal model for a totally enclosed fan-cooled induction motor," Electric Power Components and Systems, vol. 40, pp. 179-194, 2011.

[7] R. Jebahi, et al., "One-dimensional lumped-circuit for transient thermal study of an induction electric motor, " International Journal of Electrical and Computer Engineering (IJECE), vol. 7, pp. 1714-1724, Aug 2017.

[8] X. Ying, "Performance evaluation and thermal fields analysis of induction motor with broken rotor bars located at different relative positions," IEEE Transactions on Magnetics, vol. 46, pp. 1243-1250, May 2010.

[9] Z. Liu, et al., "Electromagnetic and temperature field analyses of winding short-circuits in DFIGS," in Diagnostics for Electric Machines, Power Electronics and Drives (SDEMPED), 2013 9th IEEE International Symposium on, pp. 269-273, 2013.

[10] P. M. de la Barrera, et al., "Multi-domain model of induction motor with stator core faults," in International Conference on Industrial Technology ( ICIT), 2012, pp. 913-919.

[11] L. Beran, "Thermal effect of short-circuit current in low power induction motors," in 2008 13th International Power Electronics and Motion Control Conference (EPE-PEMC 2008), pp. 782-786.

[12] L. Schreier, et al., "Operation of five-phase induction motor after loss of one phase of feeding source," Electrical Engineering, vol. 99, no. 1, pp. 9-18, March 2017.

[13] M. Jannati, et al., "A novel method for IRFOC of three-phase induction motor under open phase fault," International Journal of Power Electronics and Drive System (IJPEDS), vol. 6, no. 3, pp. 439-448, Sept 2013.

[14] M. Jannati, et al., "Modelling of a 3-phase induction motor under open-phase fault using Matlab/Simulink," International Journal of Power Electronics and Drive System (IJPEDS), vol. 7, pp. 1146-1152, Dec 2016.

[15] M. Jannati, et al., "Modeling of balanced and unbalanced three-phase induction motor under balanced and unbalanced supply based on winding function method," International Journal of Electrical and Computer Engineering (IJECE), vol. 5, pp. 644-655, Aug 2015.

[16] N. Bianchi, et al., "Thermal analysis of a five-phase motor under faulty operations," IEEE Transaction Industrial Applications, vol. 49, pp. 1531--538, Jul/Aug 2013. 


\section{BIOGRAPHIES OF AUTHORS}

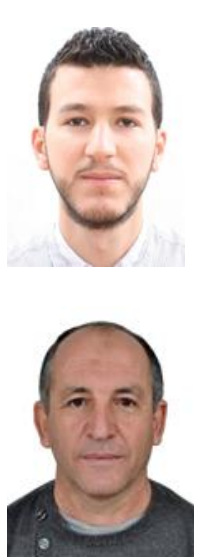

Mahdi Atig was born in Tizi-Ouzou, Algeria, on February 06, 1989. He received the B.Sc. M.Sc. degrees in electrical engineering from Mouloud Mammeri University, Tizi-Ouzou, Algeria, in 2011 and 2013, respectively. He is currently pursuing the Ph.D. degree at the LATAGE laboratory, Mouloud Mammeri University, Tizi-Ouzou. He is working on the effect of defects on the thermal behavior of electrical machines.

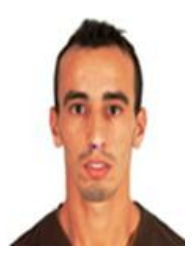

Mustapha Bouheraoua was born in Tizi-ouzou, Algeria. He received the Ph.D. science degree in electrical engineering from Mouloud Mammeri university, Tizi-ouzou, Algeria, in 2008 and the university habilitation in 2012. He is currently teaching researcher at the electrical engineering department at the faculty of Electrical Engineering in Tizi-ouzou, Algeria. His research interests include fault detection problems in electrical machines and drives, and thermal problems in electrical machines.

Arezki Fekik was born in Tizi-Ouzou, Algeria, on May 20, 1990. He received the B.Sc. M.Sc. degrees in electrical engineering from Mouloud Mammeri University, Tizi-Ouzou, Algeria, in 2011 and 2013, respectively. He is currently pursuing the Ph.D. degree at the LATAGE laboratory, Mouloud Mammeri University, Tizi-Ouzou. He is working on the application of modern control methods (Fuzzy, neurone Petri nets...), AC/DC converters and Multicellular chopper. 